\title{
Optimistic Fiction as a Tool for Ethical Reflection in STEM
}

\author{
Kathryn Strong Hansen ${ }^{1}$ (D)
}

Accepted: 25 February 2021 / Published online: 22 March 2021

(c) The Author(s) 2021

\begin{abstract}
Greater emphasis on ethical issues is needed in science, technology, engineering, and mathematics (STEM) education. The fiction for specific purposes (FSP) approach, using optimistic science fiction texts, offers a way to focus on ethical reflection that capitalizes on role models rather than negative examples. This article discusses the benefits of using FSP in STEM education more broadly, and then explains how using optimistic fictions in particular encourages students to think in ethically constructive ways. Using examples of science fiction texts with hopeful perspectives, example discussion questions are given to model how to help keep students focused on the ethical issues in a text. Sample writing prompts to elicit ethical reflection are also provided as models of how to guide students to contemplate and analyze ethical issues that are important in their field of study. The article concludes that the use of optimistic fictions, framed through the lens of professional ethics guidelines and reinforced through ethical reflection, can help students to have beneficial ethical models.
\end{abstract}

Keywords Fiction for specific purposes $\cdot$ Interdisciplinarity $\cdot$ STEM pedagogy $\cdot$ Ethical reflection $\cdot$ Science fiction

\section{Introduction}

The importance of ethics training in science, technology, engineering, and mathematics (STEM) fields is seemingly self-evident. Yet information about how to teach ethics is seldom a part of instructor training, even though the inclusion of socio-environmental factors into science education has been shown to increase students' motivation for and enjoyment of their studies (Herreid, et al., 2012; McKim, 2010; Steele, 2016). Education in STEM disciplines is needed for discipline-specific ethics (Børsen et al. 2020; van den Hoven, 2016), and case studies have long been employed for that purpose (Barden et al., 1997). Practitioners justify teaching ethics through case studies with a range of different rationales, including that 'there are ethical land mines everywhere' and 'many scientists act or speak as if they bear no responsibility for the use of their discoveries-as if their job is to uncover the secrets of the universe irrespective of the consequences' (Herreid et al., 2012,

Kathryn Strong Hansen

strong@chalmers.se

1 Chalmers University of Technology/Chalmers tekniska högskola, Göteborg, Sweden 
p. 268). Additional justifications for case studies are that cases allow for the connection of ethical concepts to real-world scenarios (O'Flaherty \& McGarr, 2014) and that they promote active learning (Montel et al., 2018, p. 158). However, all of these justifications are also true of fiction as a basis for ethical discussion and reflection.

I suggest that fiction be employed in the fiction for specific purposes (FSP) approach (Hansen, 2018) ${ }^{1}$ to serve as the foundation for writing and discussion activities that habituate students to ethical reflection. In this article, I explain how fiction is useful in pedagogical interventions to teach ethical reflection, and I delineate the ways in which optimistic fictions in particular benefit STEM students. I offer examples of optimistic fictions as well as practical examples of some of the ways that they can be employed. I focus upon science fiction to maintain reasonable limits on the scope of the discussion, and for thematic coherence my examples all employ the examination of fictions concerning artificial intelligence (AI). However, it should be noted that more than just science fiction texts can be put to the uses that I discuss here, and my limited scope is due to reasons of space rather than limitations of the FSP approach. Further, I confine my argument to ethical issues related to students' fields of academic study as distinct from, for instance, academic ethics more broadly, personal ethics, or the philosophical study of ethics, because pedagogy that includes those different facets of ethics requires targeted approaches for each respective focus.

\section{Fiction for Specific Purposes (FSP)}

Fiction holds great potential for science pedagogy in part because it heightens interdisciplinarity in STEM in beneficial ways. Fiction in STEM education has been used as a way for students to reflect upon Grand Societal Challenges (Bina et al., 2017) and stimulate opinion-forming skills (Knippels et al., 2009). The creativity-stimulating capabilities of fiction are further reason that it is useful for STEM students (Ottino \& Morson, 2016). In fact, there is a long-standing relationship between scientists and fictions as creative inspiration, because 'when we look at the lives of our most creative scientists, we discover that they all counted literature as being central to their creativity' (Camplin, 2013). From a neurological perspective, fiction's ability to enhance creativity might be at least partially explained by the suggestion that the reading of fiction strengthens connectivity in the brain (Bergland, 2014; Berns et al., 2013). Some neurological research also suggests that reading of fiction may trigger, via the brain's mirror neurons, a greater awareness of different points of view (Armstrong, 2013), which adds empathy as a potential benefit of reading fiction.

Fiction also possesses the ability to give readers a broader perspective than any one person can cultivate through his or her personal experiences. Fiction supplies experiences that most individuals cannot expect to have, or, put another way, 'fiction allows you to live more lives in the space-time of one lifetime than you would normally be able to. It allows you to benefit from the outcome of simulations without being exposed to the dangers or

\footnotetext{
1 In this earlier article, I used the phrase 'literature for specific purposes.' I have changed this phrase to be 'fiction for specific purposes' for two reasons. One reason is that cinematic and televisual fictions could be used in this approach, and I have sought to allow for their inclusion with the more inclusive term 'fiction.' The second reason is that the term 'literature' is often used in STEM contexts to indicate secondary sources or research articles, and I do not wish to foster confusion by using that term. However, I do sometimes quote from sources that use 'literature' and I have therefore preserved their verbiage so as not to change other authors' work. Additionally, the phrase 'literary analysis' is a specific term, and I have not modified it despite my choice to use 'fiction' as a broader, more inclusive term.
} 
time constraints that you would be forced to undergo if you had to live every experience that informs your reality by yourself' (Rosen, 2013). In this way, fiction offers similar benefits to those offered by case studies, but additional benefits exist with fiction. For instance, fiction provides greater historical perspective than any one lifetime can supply, because the humanities involve an expansive view of knowledge that spans humankind's history (Bush, 1959; Mar \& Oatley, 2008), whereas scientists must by necessity focus their attention on the latest studies and most recent developments in their field.

But perhaps one of the most salient benefits of fiction is that, while it may represent characters and situations realistically, it does not actually replicate reality. This has several key implications when using fiction in the teaching of ethics, including the possibility for a literally limitless set of possible ethical issues to be addressed. Fiction's existence outside of reality means that 'narrative can be seen as a vehicle by which people test various scenarios without risking too much' (Vermuele, 2009, p. 41). The lack of risk on the part of the student inheres in the fact that case studies present real-world examples or have likely real-world correlates. If students presume that 'correct' answers exist because the cases are real and therefore have an instructor-sanctioned solution, students might select the solution that they guess to be the one that their instructor wants. In contrast, fiction's removal from reality makes students risk less in staking a stance on an ethical situation. It is generally understood that literary analysis is an interpretative activity, and well-constructed fictions seldom have only one interpretation. Effectively, this results in there being no one foregone answer to ethical dilemmas drawn from fiction, and students' general awareness of this may then help them to be more authentic in their ethical reasoning.

FSP capitalizes on all of these benefits of fictions. It is an applied rather than theoretical humanities approach. It involves using fictions, including cinematic, televisual, and textual fictions, to teach sociocultural aspects of STEM. FSP targets the needs of a particular set of students, the particularity coming from a shared field of study (such as organic chemistry) or from a specific topic (such as nanomaterials). This particularly dictates the selection of reading materials and the focus of course assignments. FSP ties all of these components together by using the pedagogical tool of literary analysis.

Literary analysis is the method through which literary critics 'make interpretations of particular texts' (Kusch, 2016, p. 108). Literary thinking - the careful examination of narrative, plot, character, and other elements to come to a greater understanding about key issues in a text and identify patterns within a text - emphasizes the relationship of part to whole. Similar thinking is key in the scientific method, which involves inductive logic (the compilation of, say, individual experiments) and the generation of a hypothesis (which can make general claims about many specific individual observations) (Gower, 1996). One vital method of literary analysis is close reading. While this term's definition is contested amongst scholars of narrative, at its core it can be said to involve focusing on a text's details and engaging in sustained reflection and analysis of the text and its larger implications both intradiegetically and extradiegetically (Katan \& Baarts, 2020). Close reading is, in effect, training in pattern recognition and critical analysis, and more examples of close reading in FSP will be provided later.

FSP has several pedagogical domains, each relating to an important benefit or skill that fiction offers. The six domains of FSP teaching are: ethics, critical thinking, narrative competence, creativity, intercultural awareness, and range of perspective. These domains are flexible enough to teach a wide range of specific purposes. Examples include principles of narrative for video game designers, awareness of multiple perspectives in user-centered design, critical thinking about environmental engineering concerns, and discussion of artificial intelligence ethics, just to name a few. 


\section{Benefits of Optimism}

An additional benefit of fiction as a teaching tool is that many fictions focus on positive models. In contrast, while case studies are useful resources, they can keep students' attention focused on missteps and negative examples by replicating actual ethical breaches or presenting problems analogous to real-world ethical lapses. Calls for reframing ethics training to avoid negative emphases amplify the need for approaches that provide models to emulate rather than avoid (Gentile, 2010). This is not to say that case studies or negative examples should never be used; awareness of pitfalls and the consequences of ethical failure are important components of ethical education. Case studies or fictions that use negative examples, however, should be used judiciously, and when possible, models to emulate should be selected.

Optimism has been established as desirable for college students in many ways. For one, optimism is beneficial in the process of students transitioning into university studies (Morton et al., 2014). While this applies to first-year students, it also aids students who transfer institutions or programs. An optimistic mindset is not only beneficial for young adults but provides benefits even more broadly, such as increasing the ability to cope in times of stress (Nes \& Segerstrom, 2006; Scheier \& Carver, 1992). Demonstrated correlations between optimism and life satisfaction (Gallagher et al., 2012), as well as between higher levels of optimism and improved psychological health (Andersson, 1996; Scheier \& Carver, 1992), have also been found.

More to the point of the discussion at hand, role models have been shown to be effective in influencing people to engage in positive behavior (Harris et al., 2016; Pimple, 2007) while, on the other hand, overexposure to real-world ethical failures can contribute to students' perception that unethicality is the norm (Baden, 2014). Students need to cultivate a sense of ethicality being possible and laudatory. In fact, role models tend 'to inspire students to pursue those positive examples in their own careers' while negative models tend 'to reduce students' self-efficacy in their ethical disciplinary domain, which could create barriers to professional ethical behavior, and negative role models were also connected to a high level of student cynicism' (Baden, 2014, p. 166). The observed unethicality of others has even been suggested to influence observers to engage in unethicality (Gino et al., 2009). This research therefore suggests that greater emphasis on exemplary behavior in ethics discussions is needed to encourage the replication of ethical behavior.

One approach is to provide students with more opportunity to engage in ethical reflection in their university studies. I define ethical reflection as the cognitive exploration and interpretation of ethical issues that allow for the cultivation of critical awareness of those issues. More practically, ethical reflection involves the processing of an ethical issue in writing, so that it combines the cognitive processes of analysis and writing to produce a coherent, if tentative or not-yet-final, textual artefact that starts a dialogue with the course instructor and/or other course participants. Using optimistic fiction as the springboard for guided ethical reflection can keep students focused on achieving ethicality rather than merely avoiding unethicality. This may at first appear to be a small semantic difference, but as I have explained by providing some of the benefits of models to emulate rather than to avoid, this difference in emphasis can have an effect on whether ethical behaviors are likelier to be replicated. 


\section{Optimistic Science Fiction}

The use of science fiction has been championed in engineering programs as encouraging students 'into modes of learning that are non-traditional, self-reflective, and analytically disruptive' (Manià et al., 2017, p. 407), partially because science fiction emphasizes ideals and possibilities (Grigé, 2017; Krauss, 2014). Importantly, science fiction can also provide 'a shared vision' (Stephenson, 2014) to scientists, engineers, and technologists who might not participate in the direct exchange of ideas with one another.

Hope and optimism do not characterize every science fiction text, but a hopeful perspective characterizes the core of much science fiction, which stands in distinction to hegemonic pessimism. With science fiction, the potential exists 'to move its reader to see the differences of an elsewhere and thus think critically about the reader's own world and possibly act on and change that world' (Baccolini, 2004, pp. 519-520).

In offering possible futures that differ from the current reality in laudable ways, optimistic science fiction can offer inspirational goals for scientists and developers of technology. Science fiction relies on an assumed faith in the capabilities of such developments (Rabkin, 2004), and the optimistic models it offers can provide a rough outline of the behaviors and ethical outcomes that should be encouraged.

While dystopian tales and gritty plots have certainly been evident in science fiction, the genre of science fiction also offers optimistic fictions that can model ethical behaviors. Project Hieroglyph is one example of science fiction's commitment to cultivating optimism. Project Hieroglyph is an initiative aiming to spur technological innovation through science fiction inspiration (Project Hieroglyph, 2019). Founded in 2011 by the science fiction writer Neal Stephenson, Project Hieroglyph's stated goal is to 'reignite humanity's grand ambitions for innovation and discovery' by placing scientists, technologists, and engineers into conversation and collaboration with writers and artists (Center, n.d).

Project Hieroglyph is enacted in conjunction with Arizona State University's Center for Science and the Imagination, which also houses a website for 'Thoughtful Optimism and Science Fiction.' The criteria for thoughtfully optimistic science fiction are that it: (1) spotlights positive human traits and behaviors or delivers 'some sort of hopeful beat or beautiful moment,' even if the surrounding environment is bleak; (2) encourages innovation rather than defeatism or stagnation; (3) portrays scientific discoveries and technologies as constructive rather than ruthless; and (4) depicts innovation ecosystems' where solutions to grand challenges are created to make society more just, equitable, and sustainable (Nguyen, 2014). These characteristics lend themselves well to ethical discussions of STEM with their emphasis on innovation and societal benefit.

Solarpunk is another example of optimistic science fiction, as solarpunk is a subgenre of science fiction offering optimistic possible futures that have optimistic approaches to environmental concerns ('Solarpunk', 2019). Solarpunk espouses a more optimistic perspective than its namesake cyberpunk, which often presents dark and dystopian futures. The literary lineage of solarpunk includes utopian literature in its focus on the possibilities more than the drawbacks of future (Johnson, 2020). Consequently, 
it offers hope and optimism, even if its plots are not completely free from conflict. One follower of solarpunk put it this way: 'We're solarpunks because the only other options are denial or despair' (Flynn, 2014; emphasis in original); this perspective directly opposes dystopia, implicitly aligning the ideals of solarpunk with optimism.

A great deal of other contemporary science fiction provides optimism. For instance, Andy Weir's The Martian (2011) tells the Robinson-Crusoe-like story of an astronaut forced to use his cleverness and skills to survive alone on Mars, providing hope that humanity's persistence will be a benefit to space exploration. This novel, like the 2015 movie of the same name that is based upon it, raises a host of ethical questions about space travel, such as whether to prioritize the preservation of one person's life over the preservation of the lives of a group. The Expanse book series (2011- ongoing, and also an ongoing television series) by James S.A. Corey similarly places protagonists in danger, generally concerning the competing interests of those who live on Earth, on Mars, and within an asteroid belt. In this series, the crew of the spaceship Rocinante work to stop a galaxy-spanning civil war and to try to ensure that resources are distributed equitably among different groups. Despite the issues and strife in the novels, short stories, and novellas that comprise this ongoing series, many of its characters show that humankind will, even despite the existence of competing factions, have those who fight for fairness.

Many televisual and filmic fictions also exemplify optimism. One popular example is Doctor Who (1963-1989, and 2005-ongoing), which presents the adventures of an advanced alien who so admires humankind that he appoints himself its protector even though doing so often places him in danger, repeatedly displaying faith in the potential and possibility of humankind (Levy, 1985). The central character travels through time and space with human companions, whom the show constructs as using the perspectives on life and morality gained from their time with the Doctor to help others after their adventures with him end. The Star Trek franchise (1966-ongoing) is another generally optimistic option, spanning several television series as well as a spate of movies. This franchise depicts alien races working toward a shared goal of exploration, and has long engaged in diverse casting so as to further underscore the theme of inclusivity (Cavna, 2016). Though its long life makes it difficult to identify one central message that it imparts, the Star Trek fictions have generally espoused reason and tolerance as hallmarks (Saadia, 2016).

These fictions are just a few examples of those which offer ethical role models in the many characters they depict. In so doing, they provide material for reflection assignments that focus on actions that should be emulated. Exemplary models enhance observers' likelihood to engage in prosocial behavior (Schnall et al., 2010) and to exhibit various ethical behaviors (Haidt, 2000). Emulating good examples has been found to encourage ethical decision making amongst nursing students (Pang \& Wong, 1998) as well as engineering students (Han, 2015), suggesting widespread benefit for the use of positive examples. Additionally, the development of moral courage in business students has been shown to require examples of those who have exercised moral courage (Comer \& Schwartz, 2017). This allows for scaffolded writing reflection prompts that emphasize the positive, and the morally courageous, so as to be more likely to elicit ethical decision-making from students.

\section{Using Optimistic Science Fiction in FSP}

Science fiction can be used as the underpinning for discussion of ethical dilemmas that is aspirational, creating the possibility to model ethical ideals. One primary example will serve as an introduction here, but many such fictions could be used in the FSP approach, 
which holds the potential for a broad range of possible applications for the employment of ethical reflection. Fictions that depict as-yet-unrealized developments can be used to allow students to reflect not on the ethics of specific technologies or particular aspects of science, but on scientific enterprises more broadly. One example of a hopeful fiction that works well for this is Ted Chiang's short story 'The Truth of Fact, the Truth of Feeling' (Chiang, 2013). This narrative interrogates the changes that technology can make to individuals with two plots: one is that of a narrator in the future who uses a technology called Remem to access recordings of his own behavior and who is forced to reevaluate his relationship with his daughter, and the other is that of an African from the past learning that reading and writing are technologies that profoundly shift his understanding of truth. In both of these cases, a character's exposure to a technology transforms him in ways that each at first finds troubling. However, Remem allows the narrator to gain a stronger sense of himself as well as a clearer understanding of his relationship to his daughter, and the technology of writing helps the character Jijingi deepen his appreciation for his culture's conception of different kinds of truth. Both of these characters gain wisdom through their exposure to technology, even if the wisdom is hard-won, showing that technology can be a potent tool for personal growth.

'The Truth of Fact, the Truth of Feeling' can serve as the springboard for discussion on how technology changes society, and it can also guide students to think about how technology has ramifications for individuals' personal lives. This, of course, is a possibility for all technological and scientific developments, so this discussion can be a stepping stone for students to reflect upon the ethical ramifications of such impact as it concerns their own specific STEM projects and pursuits. The fact that Chiang's story includes positive outcomes for at least some of its characters may free students from a sense that their work must necessarily bring harm, as could be inferred from much dystopian fiction. Students' reflection upon both advantages and disadvantages of their own work can also help point out to them that, like the narrator and his daughter or like Jijengi and his village elders, a benefit for one person might be a drawback for another.

To shape the way that students read, questions are helpful when their distribution precedes students' reading so as to guide their focus during the reading of the assigned fictions. It is also useful to use such reading questions to direct students' attention to key issues in the fiction prior to having them engage in written ethical reflection. Different ways of approaching any text are possible, and different readers might focus on different plot points or themes. Therefore, calling students' attention to the issues most closely in alignment with the intended learning outcomes of the specific text as well as the course is more likely to prevent students from exploring tangential, unrelated issues. For an example set of questions with which to guide students' reading of 'The Truth of Fact, the Truth of Feeling' (Chiang, 2013), see Table 1.

The questions in Table 1 include general questions intended to guide students in their close reading of the story so that they encouraged to notice details, structural elements, and language choices that might affect their understanding of the story. These questions push students to examine items in the fiction in addition to the plot points of the narrative, and these questions can be used with any fictional text to help habituate students to looking for details in the stories. Close reading thus serves as 'a form of defamiliarization we use in order to break through our habitual and casual reading practices' (Showalter, 2003, p. 98). This matters because ethical reflection should not be incidental, but purposeful, and therefore casual practices are counterproductive to such reflection. Moreover, close reading helps students to avoid accepting presumptions and expected meanings of texts (Madon, 2019), or what Jane Gallop calls reading 'NOT what SHOULD BE on the page but what 
Table 1 Reading questions for Ted Chiang's short story "The Truth of Fact, the Truth of Feeling"

Questions to encourage close reading (pre-reading)
Questions to encourage ethical reflection (postreading)
- What is/are the setting(s) for this story?

- Whose point(s) of view do readers experience? Why do you think this is how the story is structured?

- In a sentence or so, what do you think is/are the main theme(s) of the story?

- After examining the story closely, do you see any figurative language (metaphors, for instance)? Are there any words or phrases with ambiguous or double meanings?
- Chiang's story suggests that technology changes us in ways that we perhaps cannot foresee. Without knowing how AI will change humanity, how can we best ensure ethical decision making in AI design and creation?

- The narrator says: "We don't normally think of it as such, but writing is a technology, which means that a literate person is someone whose thought processes are technologically mediated. We became cognitive cyborgs, as soon as we became fluent readers, and the consequences of that were profound." Does this suggest that any technological cognitive aid essentially makes our own intelligence artificial in some way? If so, how might this be construed as a benefit?

- Jijingi starts to see the world differently once he learns to write. For example, he slowly learns the concept of "words," and even more slowly realizes that "words were not just the pieces of speaking; they were the pieces of thinking." Are his changes in thinking desirable shifts of viewpoint? What benefits and what drawbacks do his perspective shifts bring?

- The narrator indicates from where the story's title comes by referencing Roy Pascal's writing about the concept of autobiography. But what do you think is the difference between "the truth of fact" and "the truth of feeling"?

- If Remem were real, would you want to use it? Why or why not?

- The narrator asserts, "the best I can do is look for something positive in" digital memory. Does this point of view change how the technology works for him in any significant way? Why or why not?

- The story includes this idea: "But in my choice of which details to include and which to omit, perhaps I have just constructed another story." Because so much of AI implementation relies on data, how can creators of AI be sure that that their data choices are not only ethical, but realistic?

IS' (Gallop, 2000, p. 8; emphasis in original). This is a more data-driven and fact-based approach, creating methodological overlap with scientific approaches.

Other questions to encourage ethical reflection call attention to aspects of the fiction that raise broad ethical questions about STEM developments. These are dependent upon the fictional text that has been selected. In the case of Chiang's story, that includes the bifurcated storyline that pushes readers to compare the emotional and technological situations of the narrator and the character of Jijingi. Students' personal opinions are solicited in questions like, from Table 1, 'If Remem were real, would you want to use it? Why or why not?' While this is a question that is based on a specific technology, that technology's fictional status allows this question to serve as a springboard to discussion that more broadly assesses how students decide whether a technology compromises their own privacy or negatively impacts 
their relationships. In turn, such discussion lends itself to exploration of issues of how the students, as engineers and innovators, should keep these issues in mind as they develop implementations that will affect other people. Other questions, such as 'Chiang's story suggests that technology changes us in ways that we perhaps cannot foresee. Without knowing how AI will change humanity, can we make fully ethical choices about it? Why or why not? If so, how?' encourage students to think more generally about the ethical implications of currently existing technologies. Important to note here is that almost all of the framing of these questions focuses on the positive; this includes not only casting technology in a generally positive light, but also proceeding with the implied assumption that the ethical dimension is a key element in considering the development and implementation of real-world technology.

\section{Ethical Reflection}

Written reflection is a key component of FSP, because the articulation of ideas in written form requires planning and analysis. Writing as a way to generate knowledge or understanding has been suggested to help create networks of ideas (Klein \& Unsworth, 2014) and improve student performance in courses (Balgopal et al., 2018), and it may foster the clarity and formulation of specificity that is necessary in the taking of successful action (Schippers et al., 2020). Written reflection also reinforces the relevance and importance of an issue to students (Brewer \& Jozefowicz, 2006).

Reflecting about ethics capitalizes on these strengths of writing as an activity, and it asks students to probe deeply what they know. It can also ask students to press their acceptance of assumed or expected knowledge. As Donald Schön has written, reflective practice is 'a reflective conversation with the situation' (Schön, 1983, p. 295), or in other words, it is a conscious awareness of the fact-based contours of a situation rather than a willingness to see the situation as one expects or perhaps desires it to be. Fiction is useful in this type of reflection, especially when it presents as-yet-unrealized technologies; it is less likely that students have well-developed expectations of fictional developments, so engaging in reflection about the ethicality of such developments has a likelihood of making students think about these technologies' ethics for the first time (or, at least, such thinking is still apt to be novel rather than rote). To develop students' ethical reflection habit, some discussion questions can be repeated for different fictions in the same course, perhaps asked as a way to use a short writing task to begin class discussion of a text. For instance, these repeated investigations include questions like 'who benefits?,' 'who suffers?,' and 'is the ethical quandary solved in a way that maximizes benefits or increases suffering for characters?' Such questions focus on the effects of a technology or scientific development on individual humans as well as on humankind more broadly, allowing for subsequent discussion to connect to ethical issues more easily (particularly when using utilitarianism, or the branch of ethics that focuses on the consequences of actions and behaviors).

Another approach is to construct a reflective writing prompt for a longer piece of writing, such as a report, that builds on the assumption that engineers and technologists want to conduct their work ethically. For example, such a prompt might read: 'Write a text that explains how an AI issue in the text relates to a current ethical issue regarding AI. The problem/goal statement in your report should answer the question: What ethical AI issue does the fictional text contain, and how might real-world AI creators incorporate ethical reflection on this issue into their work?' The question that students are to answer here takes as a given that AI creators will take ethical consideration as a necessary component of their work. 
Note that this example prompt would follow after in-class discussion (and/or, as the situation warrants, discussion on an online learning management system's discussion board). Fiction's remove from reality (discussed in the 'Fiction for Specific Purposes' section of this article) provides an arena of diminished risk within which to discuss issues, but ethical choices may, in actual situations, involve professional or intellectual risk. An ethical reflection assignment will therefore help bridge the students' thinking from fiction-centered issues to ethical issues in real practice. Reflection is a pedagogical tool that connects theory and 'uncertain situations' (McGuire et al., 2009, p. 93), making it particularly useful in the analysis of difficult ethical choices, which by definition do not have certain or obvious solutions. Further, written reflection can encourage students to connect personal notions to professional contexts in a venue that allows for sustained student/teacher discussion (McGuire et al., 2009). Because it is the sociocultural dimensions of STEM issues in which the ethical ramifications of scientific and technical developments can be explored, the inherent emphasis in fiction on sociocultural dimensions is of particular use when using fiction to inspire ethical reflection.

\section{Modeling Ethics with Guidelines}

A key element to the FSP approach for encouraging ethical reflection is the use of guidelines from industry or from other organizations involved with ensuring ethical conduct. Professional ethics guidelines help delineate a field's consensus on ethical issues of concern for that field. Yet in increasingly international academic and professional contexts, legal statutes alone cannot be guides because the legal codes for different countries might differ, and the possibility exists that they will differ greatly. However, it is important to emphasize that such guidelines are useful in discussing the ethical issues that industry leaders recognize as key with a technology or scientific advancement, even though they are 'not a complete system for complex ethical decision making' (Winter, 2020, p. 21; emphasis in original).

In the FSP approach, professional guidelines serve much the same purpose as literary theory serves in more traditional (i.e. theoretical rather than applied) literary analysis, which is to provide a lens with which to approach fictional texts. The guidelines ideally should be used not to establish the final word on how to adjudicate ethical issues but to help students delineate the current conversations about ethics in their field and therefore shape their own thinking on important ethical issues in their disciplines. It is a good idea for instructors to select some fictions that include speculative technologies or not-yet-realized implementations so as to push the boundaries of current ethical discussions beyond what is covered in such professional guidelines. In this way, students can begin to formulate their own ideas about how to consider ethics in a changing scientific or technological landscape. The guidelines serve as touchstone texts, but the onus for thinking through speculative developments' ethical implications remains on the students.

Additionally, the approach taken by each particular guideline is important to consider when selecting material for an FSP intervention. Take, for example, Ethically Aligned Design: A Vision for Prioritizing Human Well-being with Autonomous and Intelligent Systems. The stated goal of that publication is to encourage and educate those who develop autonomous and intelligent systems to prioritize ethical considerations when they create such systems (IEEE, 2017). The guidelines use a positive frame, as the wording here does not stress avoidance, negation or rejection, but instead uses the far more optimistic goal of ensuring 'that these technologies are advanced for the benefit of humanity' (IEEE, 2017, 
p. 3; emphasis mine). While the guidelines do later employ language of negation, such as in the statement of one goal that the design of autonomous and intelligent systems "do not infringe on internationally recognized human rights" (IEEE, 2017, p. 6; emphasis mine), the general tenor of the publication is one of aspirational and optimistic expectation.

Similarly, the European Commission's High-Level Expert Group on AI has set forth guidelines for trustworthy AI that frame their expectations for AI in positive terms. They specify that trustworthy AI should be lawful, robust, and ethical, constructing their conception of AI in positive terms (European Commission High-Level Expert Group, 2019). In contrast, guidelines that emphasize pessimistic points of view, such as those that support the idea that a technology is ripe for misuse, maintain focus on negativity and should therefore be cautiously employed. Whether professional guidelines are pessimistic or optimistic in tone, such framing of the guidelines should be discussed explicitly with students. Students should be directed to examine guidelines' language for positive or negative framing. If students use a guideline that is framed in negative or pessimistic language, one activity to shift the discussion toward optimism is to ask students to reformulate some pertinent passage or passages so as to reflect a positive rather than negative stance. In so doing, students can then keep their own focus more optimistic and aspirational, as well.

\section{Conclusion}

The ethical and moral underpinnings of STEM work must be core elements in STEM education, and optimistic approaches may well create the likeliest conditions to encourage students' ethical decision-making. In no small part because they create aspirational models, optimistic examples are needed to help establish ethical norms for students to follow, and the FSP approach is a framework that can aid in the dissemination of such examples.

Optimistic fictions serve both psychological and practical ends. In addition to increasing students' perceptions of life satisfaction and reducing stress, optimistic approaches are likelier to encourage students to replicate positive models in their own ethical choices. Optimistic science fiction more particularly is beneficial in offering inspirational goals that relate to STEM students' chosen careers, and these texts that offer hope and possibility chart possible endpoints for current and potential future ethical quandaries.

One possible limitation is important to note, and that is that the specific context in which a program or course is taught dictates a great deal about how FSP interventions should be used. For instance, a study in Canada that explored responses to positive or negative role models showed that Canadians of European descent were more motivated by positive role models while Canadians of Asian descent were more motivated by negative role models (Lockwood et al., 2005). This example indicates that cultural contexts matter, and the same is likely true of intellectual and geographical contexts, as well. A sensitivity to and awareness of such specific aspects of a student population is therefore important in planning any FSP approach, and further studies regarding responses to optimistic fictions are needed to delineate cultural differences that can impact the use of those fictions in ethical reflection training.

Other practical limitations may affect how the FSP framework is used. For instance, many programs may not see how to create room for a separate ethics course, and so this framework would then need to be adapted to allow for smaller ethics units to fit within existing courses. This presents challenges in preserving necessary existing content in those courses while simultaneously creating space for students to read and analyze a fiction as 
well as submit a written reflection upon it. Ways to make that possible would include using one, or perhaps two, short fictions and creating a written reflection assignment that does not add unduly to the students' workload. These adaptations may require the aid of a literary critic, so interdisciplinary collaboration between the STEM content professor and a literature professor could prove useful. However, such collaboration may itself provide a limitation, as institutions might disincentivize interdisciplinary collaboration or team teaching by, for example, diminishing or ignoring it in tenure and promotion decisions.

By capitalizing on the benefits of fiction, which include its emphasis on a range of points of view, and its separateness from reality, instructors can offer students an interdisciplinary path toward the cultivation of ethical reflection habits. I have argued that an approach which foregrounds optimism beneficially models ethical reflection, but this is not a call to exclude totally the use of negative or dystopian material. For instance, Mary Shelley's classic science fiction novel Frankenstein: Or, the Modern Prometheus (1818), which presents one of the most famous examples of poor scientific ethics, has stood the test of time as a touchstone of scientific ethics discussion and sets forth norms for the scientific community about danger, ethical behavior, and creators' responsibility to what they create (Nagy et al., 2020). However, models for students to emulate create a clearer sense of what is possible for those who commit to ethical fortitude. Optimistic science fiction, as I have argued, provides a wealth of narratives that supply the benefits of fiction, scientific and general content that facilitate ethical reflection, and emulative models to foster ethical decision-making. Its more widespread use in STEM education offers the possibility to encourage greater ethical reflection, and further practical applications of the FSP framework and of optimistic fictions are needed to help establish their more frequent use.

Funding Open access funding provided by Chalmers University of Technology.

Open Access This article is licensed under a Creative Commons Attribution 4.0 International License, which permits use, sharing, adaptation, distribution and reproduction in any medium or format, as long as you give appropriate credit to the original author(s) and the source, provide a link to the Creative Commons licence, and indicate if changes were made. The images or other third party material in this article are included in the article's Creative Commons licence, unless indicated otherwise in a credit line to the material. If material is not included in the article's Creative Commons licence and your intended use is not permitted by statutory regulation or exceeds the permitted use, you will need to obtain permission directly from the copyright holder. To view a copy of this licence, visit http://creativecommons.org/licenses/by/4.0/.

\section{References}

Andersson, G. (1996). The benefits of optimism: A meta-analytic review of the Life Orientation Test. Personality and Individual Differences, 21(5), 719-725.

Armstrong, P. B. (2013). How Literature Plays With the Brain: The Neuroscience of Reading and Art. Johns Hopkins University Press.

Baccolini, R. (2004). The persistence of hope in dystopian science fiction. PMLA, 119(3), 518-521.

Baden, D. (2014). Look on the bright side: a comparison of positive and negative role models in business ethics education. Academy of Management Education and Learning, 13(2), 154-170. https://doi. org/10.5465/amle.2012.02512012.0251

Balgopal, M. M., Casper A. M., Wallace, A., Alison M., Wallace, Paul J., \& Brisch, E. (2018). Writing Matters: Writing-to-learn activities increase undergraduate performance in cell biology BioScience 68445 454 https://doi.org/10.1093/biosci/biy042

Barden, L. M., Frase, P. A., \& Kovac, J. (1997). Teaching scientific ethics: A case studies approach. The American Biology Teacher, 59(1), 12-14. https://doi.org/10.2307/4450233 
Bergland, C. (2014). Reading fiction improves brain connectivity and function. Psychology Today (4 January). Accessed 4 November 2016. https://www.psychologytoday.com/blog/the-athletes-way/201401/ reading-fiction-improves-brain-connectivity-and-function

Berns, G. S., Blaine, K., Prietula, M.J., Pye, B. E. (2013). Short- and long-term effects of a novel on the connectivity in the brain. Brain Connectivity, 3.6 (9 December): 590-600. Accessed 4 November 2016. http://online.liebertpub.com/doi/abs/10.1089/brain.2013.01662013

Bina, O., Mateus, S., Pereira, L., Caffa, A. (2017). The future imagined: Exploring science fiction as a means of reflecting on today's Grand Societal Challenges and tomorrow's options. Futures, 86, 166184. https://doi.org/10.1016/j.futures.2016.05.0092016.05.009

Bush, D. (1959). Education and the humanities. Daedalus, 88, (1, Winter): pp. 40-55.

Børsen, T., Serreau, Y., Reifschneider, K., Baier, A., Pinkelman, R., Smetanina, T., \& Zandvoort, H. (2020). Initiatives, experiences and best practices for teaching social and ecological responsibility in ethics education for science and engineering students. European Journal of Engineering Education. https:// doi.org/10.1080/03043797.2019.17016322019

Brewer, S. M., \& Jozefowicz, J. J. (2006). Making economic principles personal: Student journals and reflection papers. Journal of Economic Education, 37(2), 202-216.

Camplin, T. (2013). Scientists and engineers need literature. The John Williams Pope Center for Higher Education Policy (7 April). Accessed 19 January 2018. https://www.jamesgmartin.center/2013/04/ scientists-and-engineers-need-literature/2013/04/scientists-and-engineers-need-literature/

Cavna, M. (2016). A series that boldly went - for inclusion. The Washington Post (20 July). Accessed via Ebsco Host.

Chiang, T. (2013). The truth of fact, the truth of feeling. Subterranean Magazine. Fall. Accessed 20 August 2020. https://subterraneanpress.com/media/ebooks/SubPressFall2013.epub2013.epub

Center for Science and the Imagination. (n.d.). Arizona State University. https://csi.asu.edu/

Comer, D. R., \& Schwartz, M. (2017). Highlighting moral courage in the business ethics course Journal of Business Ethics 146703723 https://doi.org/10.1007/s10551-015-2919-3

European Commission High-Level Expert Group on AI. (2019). Ethics guidelines for trustworthy AI. Accessed 13 August 2020. https://ec.europa.eu/digital-single-market/en/news/ethics-guidelines-trustworthy-ai

Flynn, A. (2014). Solarpunk: Notes toward a manifesto. Hieroglyph. Accessed 20 August 2020. https:// hieroglyph.asu.edu/2014/09/solarpunk-notes-toward-a-manifesto/2014/09/solarpunk-notes-toward-amanifesto/

Gallagher, M. W., Lopez, S. J., \& Pressman, S. D. (2012). Optimism is universal: Exploring the presence and benefits of optimism in a representative sample of the world. Journal of Personality, 81(5), 429440. https://doi.org/10.1111/jopy.12026

Gallop, J. (2000). The ethics of reading: Close encounters. Journal of Curriculum Theorizing (Fall): 7-17.

Gentile, M. C. (2010). Giving Voice to Values: How to Speak Your Mind When You Know What's Right. Yale UP.

Gino, F., Ayal, S., Ariely, D. Contagion and differentiation in unethical behavior: The effect of one bad apple on the barrel. Psychological Science, 20 (3, March): 393-398. https://doi.org/10.1111/ j.1467-9280.2009.02306.x2009.02306.x

Gower, B. (1996). Scientific Method: A Historical and Philosophical Introduction. London \& New York: Routledge.

Grigé, L. (2017). Science fiction works for the development of the aerospace sector. Space Policy, 41, 42-47. https://doi.org/10.1016/j.spacepol.2017.05.0032017.05.003

Haidt, J. (2000). The positive emotion of elevation. Prevention and Treatment 3 (1). https://doi.org/10.1037/15223736.3.1.33c

Han, H. (2015). Virtue ethics, positive psychology, and a new model of science and engineering. Science and Engineering Ethics, 21(2), 441-460. https://doi.org/10.1007/s11948-014-9539-7

Hansen, K. S. (2018). Literature for specific purposes: A literary approach to teaching ethics in science and technology. Configurations, 26(Summer), 337-343. https://doi.org/10.1353/con.2018.00302018.0030

Harris, N., Shealy, T., \& Klotz, L. (2016). How exposure to 'role model' projects can lead to decisions for more sustainable infrastructure. Sustainability, 8 (2). https://doi.org/10.3390/su8020130

Herreid, C., Schiller, N., \& Herreid, Ky. (2012). Science stories: Using case studies to teach critical thinking. National Science Teachers Association. ProQuest Ebook Central.

Institute of Electrical and Electronics Engineers (IEEE). (2017). Ethically Aligned Design, version 2. Accessed 13 August 2020. https://standards.ieee.org/content/dam/ieee-standards/standards/web/documents/other/ ead_v2.pdf

Johnson, I. (2020). 'Solarpunk' \& the pedagogical value of utopia. The Journal of Sustainability Education, 23. Accessed 5 August 2020. http://www.susted.com/wordpress/content/solarpunk-the-pedagogical-value-ofutopia_2020_05/2020_05/ 
Katan, L., \& Baarts, C. A. (2020). Inquiry-based reading - Towards a conception of reading as research method. Arts and Humanities in Higher Education, 19(1), 58-75. https://doi.org/10.1177/14740222218760261

Klein, P. D., \& Unsworth, L. (2014). The logogenesis of writing to learn: A systemic functional perspective. Linguistics and Education, 26(June), 1-17.

Knippels, M.-C., Severiens, S. E., \& Klop, T. (2009). Education through fiction: Acquiring opinion-forming skills in the context of genomics. International Journal of Science Education, 21(15), 2057-2083.

Krauss, L. M. (2014). Forward. Hieroglyph: Stories and Visions for a Better Future. Eds. Ed Finn and Kathryn Cramer. New York: William Morrow.

Kusch, C. (2016). Literary Analysis: The Basics. Routledge.

Levy, M. M. (1985). Who, what, and why? Character motivation in Doctor Who. Children's Literature Association Quarterly 10 (2, Summer): 76-79. https://doi.org/10.1353/chq0.0475

Lockwood, P., Marshall, T. C., \& Marshall, P. S. (2005). Promoting success or avoiding failure: Culture differences in motivation by positive and negative role models. Personality and Social Psychology Bulletin, 31 (3). https://doi.org/10.1177/0146167204271598

Madon, D. (2019). Why analyze a sonnet? Avoiding presumption through close reading. In From Reading to Healing: Teaching Medical Professionalism Through Literature. Susan Stagno, Michael Blackie, and Arthur W. Frank, eds. The Kent State U Press.

Manià, K., Mabin, L., \& Kathleen; and Liebenberg, Jessica, . (2017). 'To go boldly': Teaching science fiction to first-year engineering students in a South African context. Cambridge Journal of Education, 48(3), 1469-3755. https://doi.org/10.1080/0305764X.2017.1337721

Mar, R. A. \& Oatley, K. (2008). The function of fiction is the abstraction and simulation of social experience. Perspectives on Psychological Science, 3(3): 173-192. Accessed 4 November 2017. http://lchc. ucsd.edu/MCA/Mail/xmcamail.2009_12.dir/pdfJEO79Qqyg3.pdf2009_12.dir/pdfJEO79Qqyg3.pdf

McGuire, L., Lay, K., \& Peters, J. (2009). Pedagogy of reflective writing in professional education. Journal of the Scholarship of Teaching and Learning, 9 (1): 93-107. Accessed 17 August 2020. Retrieved from https://scholarworks.iu.edu/journals/index.php/josotl/article/view/1718

McKim, A. (2010). Bioethics education. In A. Jones, A. McKim, \& M. Reiss (Eds.), Ethics in the science and technology classroom: A new approach to teaching and learning (pp. 19-36). Sense Publishers.

Montel, I., Antolin-Lopez, R., \& Gallo, P. J. (2018). Emotions and sustainability: A literary genre-based framework for environmental sustainability management education. Academy of Management Learning and Education, 12(2), 155-183. https://doi.org/10.5465/amle.2016.00422016.0042

Morton, S., Mergler, A., \& Boman, P. (2014). Managing the transition: The role of optimism and selfefficacy for first-year Australian university students. Journal of Psychologists and Counsellors in Schools, 24(1), 90-108.

Nagy, P., Wylie, R., Eschrich, J., \& Finn, E. (2020). Facing the pariah of science: The Frankenstein myth as a social and ethical reference for scientists Science and E006 Engineering Ethics 26737 759. https://doi. org/10.1007/s11948-019-00121-3

Nes, L. S., \& Segerstrom, S. C. (2006). Dispositional optimism and coping: A meta-analytic review. Personality and Social Psychology, 10(3), 235-251. https://doi.org/10.1207/s15327957pspr1003_3

Nguyen, L. (2014). Science fiction and thoughtful optimism: A manifesto. Arizona State University Center for Science and the Imagination. https://csi.asu.edu/project-archive/optimism/science-fiction-andthoughtful-optimism-a-manifesto/

O'Flaherty, J., \& McGarr, O. (2014). The use of case-based learning in the development of student teachers' levels of moral reasoning. European Journal of Teacher Education, 37(3), 312-330. https://doi. org/10.1080/02619768.2013.870992

Ottino, J. M., \& Morson, G. S. (2016). Building a bridge between engineering and the humanities. The Chronicle of Higher Education (14 February). Accessed 29 December 2020. https://www.chronicle.com/article/ building-a-bridge-between-engineering-and-the-humanities/?cid2=gen_login_refresh\&cid=gen_sign_in

Pang, M.-C., \& Wong, K.-S. (1998). Cultivating a moral sense of nursing through model emulation. Nursing Ethics, 5(5), 424-440.

Pimple, Kenneth D. (2007). Using case studies in teaching research ethics. Ethics in Science and Engineering National Clearinghouse. 338. Retrieved from https://scholarworks.umass.edu/esence/338

Project Hieroglyph' (2019). Wikipedia. Accessed 4 November 2019. https://en.wikipedia.org/wiki/Project_ Hieroglyph

Rabkin, E. S. (2004). Science fiction and the future of criticism. PMLA, 119(3), 457-473.

Rosen, Rebecca J. (2013). Why today's inventors need to read more science fiction. The Atlantic (20 September). Accessed 22 January 2018. http://www.theatlantic.com/technology/archive/2013/09/whytodays-inventors-need-to-read-more-science-fiction/

Saadia, M. (2016). The enduring lessons of Star Trek. The New Yorker (8 September). Accessed 1 September 2020. https://www.newyorker.com/tech/annals-of-technology/the-enduring-lessons-of-star-trek 
Scheier, M. F., \& Carver, C. S. (1992). Effects of optimism on psychological and physical well-being: Theoretical overview and empirical update. Cognitive Therapy and Research, 16, 201-228.

Schippers, M. C., Morisano, D., Locke, E. A., Scheepers, Ad W. A., Latham, G. P., de Jong, E. M. (2020). Writing about personal goals and plans regardless of goal type boosts academic performance. Contemporary Educational Psychology 60 (January). https://doi.org/10.1016/j.cedpsych.2019.101823

Schnall, S., Roper, J., Fessler, \& Daniel M. T. (2010). Elevation leads to altruistic behavior. Psychological Science 21, no. 3: 315-320. https://doi.org/10.1177/0956797609359882

Schön, D. (1983). The Reflective Practitioner: How Professionals Think in Action. Basic Books.

Showalter, E. (2003). Teaching Literature. Blackwell Publishing.

Solarpunk (2019). Appropedia. Accessed 5 August 2020. https://www.appropedia.org/Solarpunk Accessed 4 November 2019.

Steele, A. (2016). Troubling STEM: Making a case for an ethics/STEM partnership. Journal of Science Teacher Education, 27, 357-371. https://doi.org/10.1007/s10972-016-9463-6

Stephenson, N. (2014). Preface: Innovation Starvation. Hieroglyph: Stories and visions for a better future. Eds. Ed Finn and Kathryn Cramer. New York: William Morrow.

van den Hoven, J. (2016). Ethics and the UN Sustainable Development Goals: The case for comprehensive engineering. Science and Engineering Ethics, 25, 1789-1797.

Vermuele, B. (2009). Why do we care about literary ch0061 racters? Johns Hopkins University Press.

Winter, S. J. (2020). Computing ethics: Operationalizing AI ethics principles Communications of the ACM 63 1218 21. https://doi.org/10.1145/3430368

Publisher's Note Springer Nature remains neutral with regard to jurisdictional claims in published maps and institutional affiliations. 